\title{
INTRODUCCIÓN A LAS LECCIONES XVII-XX: CUERPO, COMUNIDAD, LENGUAJE, MUNDO
}

Iván Ortega Rodríguez ivan.ortega79@gmail.com

Traducir la obra del autor sobre el que se investiga tiene un atractivo especial. Es contribuir a la transmisión de lo aprendido. Es facilitar el acceso a una propuesta filosófica que merece ser mejor conocida. Así ocurre en particular con las páginas que siguen. El lector encontrará la que, a mi juicio, constituye la explicación más clara y completa de la teoría de los tres movimientos de la existencia. En las lecciones que vienen a continuación, el pensador checo explica lo que le motiva a desarrollar tal teoría, por qué emplea la noción de movimiento o de qué manera se decanta en tres movimientos que forman una unidad en su diversidad.

En efecto, las lecciones de Cuerpo, comunidad, lenguaje, mundo abordan la cuestión de la existencia humana en tanto dada en primera persona y vivida corporalmente. Dicha investigación, además, no busca sólo afinar la descripción de la corporalidad vivida sino que se enmarca en un proyecto de reconsideración de la existencia humana y su relación con el mundo.

Es en el marco de este proyecto donde se sitúa la extensa exposición de la teoría de los movimientos de la existencia, que ocupa las lecciones que aquí presentamos traducidas. No es accidental que ocupen la parte final del curso. La concepción de la existencia como movimiento surge tras la exposición histórica de cómo ha ido tematizándose la perspectiva de la primera persona y tras la presentación de diversos datos fenomenológicos del existir incorporado. En el contexto de estos análisis, el movimiento se presenta como la clave para rendir cuenta satisfactoriamente del fenómeno de la existencia incorporada. ${ }^{1}$

La teoría de los tres movimientos de la existencia pretende, en primer lugar, tematizar el existente humano en la estructura y despliegue interno del ente que, en cada caso, él es. Siguiendo las aportaciones de Husserl y sobre todo Heidegger, se trata de un ente especial, a saber, aquél en quien se da la manifestación y comprende su ser y el ser en general. Con todo, para el pensador checo es necesario además preguntarse cómo es en concreto ese ente. Hay que analizar de qué manera en particular comprende su ser realizando posibilidades. Debe estudiarse de qué modo es y está en el mundo. Ahí entran dos elementos. En primer lugar tenemos la

\footnotetext{
${ }^{1}$ E-mail: ivan.ortega79@gmail.com. Una puesta en contexto de la teoría de los tres movimientos dentro del curso puede encontrarse en la recapitulación del propio Patočka al comienzo de la lección XX.
} 
corporalidad de la existencia: el existente es y comprende su ser en tanto corporal, en y desde una corporalidad vivida internamente; Heidegger ciertamente sabía de la corporalidad, reconoce Patočka, pero a su juicio dejó esta dimensión en buena medida sin tematizar. Por otro lado, está la noción de existencia como movimiento, entendido en el sentido de cambio o devenir. En efecto, el ente que existe realizando posibilidades, y que es existencia corporal, debe comprenderse como un movimiento de constituirse a sí mismo.

Ahora bien, la conceptuación de la existencia humana como movimiento exige especial cuidado. Hay que poner mucha atención en cómo se entiende este movimiento. En especial el praguense cree que se necesita un gesto de audacia filosófica, a saber, poner en interlocución a Aristóteles y Heidegger. En efecto, para nuestro filósofo la realización de posibilidades del existente debe entenderse como un movimiento de constitución del propio ser al modo de la génesis en Aristóteles. Sin embargo, esta recepción de Aristóteles no puede ser completa si queremos conservar los fenómenos constatados por Heidegger. En especial, no puede asumirse la idea de un sustrato permanente de los cambios. Antes bien, ha de entenderse que el ente humano por entero se realiza por entero en su movimiento, incluyendo el sustrato. ${ }^{2}$ En este punto, las páginas traducidas presentan probablemente la exposición más clara de esta convergencia y divergencia con Aristóteles a la hora de aplicar su concepción de movimiento a la existencia humana.

No obstante, no queda aquí la significación de la teoría de los movimientos de la existencia. Ésta no sólo busca tematizar cómo es el ente humano en su carácter de existencia realizando posibilidades. Dicha teoría busca además aprehender el hecho de que ese ente no sólo es, y está, en el mundo, sino que es también un ente del mundo, que forma parte de él. En efecto, somos el lugar donde acontece la manifestación de todo ente pero a la vez somos un ente del mundo, aunque no lo seamos como los demás entes intramundanos pues nuestro ser no nos es indiferente. Para tematizar este asunto, el pensador checo recurre a la cosmología fenomenológica de Eugen Fink, con quien Patočka mantuvo una amistad filosófica de la que se conserva una interesante correspondencia. ${ }^{3}$ Para Fink, el análisis heideggeriano sigue centrándose excesivamente en lo relativo a la existencia humana, en los fenómenos "próximos" al existente humano, como los del "desvelamiento, del encubrimiento, del sentido,

\footnotetext{
${ }^{2}$ Esta consideración de un sustrato que se iría constituyendo en el mismo movimiento, lo que por momentos se ha calificado como "radicalización de Aristóteles" ha sido especialmente desarrollado por la lectura francófona de nuestro autor. En este ámbito, además, se ha avanzado hacia las posibilidades filosóficas, las prolongaciones de esta idea, así como hacia los límites y problemas de este pensamiento. La mejor introducción a este trabajo sobre los movimientos de la existencia en la fenomenología francesa siguen siendo los trabajos de Renaud Barbaras (por más que, sin duda, puedan ser discutidos). En español pueden consultarse con provecho las páginas dedicadas a Patočka en Barbaras (2014), pp.138-193.
}

\footnotetext{
${ }^{3}$ Cf. Heitz y Nessler (1999).
} 
del fenómeno del lenguaje" (lección 19). Es preciso ocuparse del mundo como totalidad y fondo. Es necesario, explica Patočka resumiendo a Fink, ocuparse de todo lo que no se aparece, de lo que está fundamentalmente clausurado sobre sí.

Patočka concuerda con el fenomenólogo alemán. Para el checo, el movimiento de la existencia nos deja puestos en un mundo que, ciertamente, en parte se nos desvela pero que también da noticia de la totalidad omniabarcante que está fuera de nuestro alcance, que da signo de que podría existir sin nosotros y que, incluso, es condición de nuestra existencia ${ }^{4}$. De esta manera, plantea Patočka, la fenomenología nos acaba trayendo de vuelta a la noción de la naturaleza como physis. A este marco teórico que Patočka recibe de Fink se le incorpora la noción de los movimientos de la existencia para entender cuál es el lugar del ente humano en esta physis. Así, por un lado, el existente humano es un ser que surge como integrado e inserto en el mundo en virtud del primer movimiento. Es además un ente que, mediante ese mismo primer movimiento, se individua y en cierto modo se distancia en una primera fenomenización del mundo. No obstante, esa primera distancia no cuestiona la plena integración del existente en el mundo, evidenciada en el "gobierno de la tierra". Este gobierno de la tierra se extiende en la necesidad de la labor del segundo movimiento, marcado por el imperativo de mantener las condiciones para la continuación del primer movimiento. El ser humano aquí es activo, ciertamente, no está en actitud de aceptación; ahora bien, su actividad está forzada por el gobierno de la tierra sobre él, por los imperativos de su estar integrado en el mundo.

Sin embargo, frente al gobierno de la tierra en los dos primeros movimientos, en el tercero se produce un distanciamiento donde el existente se pone ante el mundo como totalidad. No estamos ya en la primera fenomenización del primer movimiento sino en una segunda donde la manifestación comparece como tal. Aquí se asiste a la donación del ente sobre el fondo del ser y el mundo se muestra como totalidad. Ésta es la instancia donde la existencia humana es lugar de la manifestación, del desvelamiento y ocultamiento del que habla Heidegger. Es en definitiva el lugar de la verdad. Ahora bien, en todo ello siguen en vigor los dos primeros movimientos, que forman con el tercero una unidad. ${ }^{5}$ Esto significa que el existente humano es, a la vez, aquél que se distancia del todo de donde se ha individuado y lo contempla en su donación, por un lado, y aquél que sigue integrado en el mundo y siendo parte de él, por el otro.

\footnotetext{
${ }^{4}$ La interlocución con Fink puede estudiarse con provecho en el breve pero denso ensayo "Universo y mundo del hombre. Observaciones a un planteamiento cosmológico contemporáneo", en Patočka (2004), pp.85-92.

${ }^{5}$ Aunque el filósofo checo habla de una oposición entre el tercer movimiento y los dos primeros, esto no cuestiona la unidad de los tres.
} 
La existencia como movimiento nos habla así de un ente que se va constituyendo a sí mismo en movimiento como un ente mundano - que forma parte del mundo y está integrado en el mismo- pero que, a través de esa misma autoconstitución en movimiento, llega a la manifestación del mundo como totalidad. Es esta articulación la que una parte de la lectura francesa de Patočka -sobre todo Renaud Barbarasconsidera como una de las aportaciones más originales de Patočka. El filósofo checo habría encontrado una fructífera clave para articular en el ser humano la "vida", que trae consigo la plena integración e inserción en el mundo, y la "existencia", que significa distanciamiento respecto del mundo. En efecto, según Barbaras, la noción de movimiento abriría la pista para superar las insuficiencias de Heidegger y Merleau-Ponty. El primero, a su juicio, entendió en profundidad la existencia pero habría pensado insuficientemente la vida, mientras que el pensador francés habría concebido adecuadamente el ser parte del mundo pero insuficientemente la manifestación y el distanciamiento. En cambio, el pensador checo habría marcado el camino a la fenomenología para pensar a la vez estos dos aspectos, por más que el propio Barbaras crea que Patočka no piensa consecuentemente hasta el final la unidad de vida y existencia. Como señala nuestro pensador checo al final de estas lecciones, se trata de pensar la existencia humana a la vez como en-el-mundo (světová) y ser del-mundo (světská).

\section{SOBRE EL TEXTO Y LA TRADUCCIÓN.}

El texto presentado se corresponde con las cuatro últimas lecciones de un curso que Jan Patočka impartió en la Universidad Carolina de Praga durante los dos semestres del curso 1968-69. ${ }^{6}$ Significó su vuelta a las aulas universitarias tras haber sido apartado veinte años antes cuando el Partido Comunista Checoslovaco se hizo con el poder. El texto está establecido a partir de las notas de un grupo de asistentes, en particular Jiří Polívka, Jaromír Kučera, Jiří Michálek, Ivan Chvatík, Miloslava Volková, Josef Vinař y Marika Krištofová. Jiř́i Polívka se ocupó de la fijación del texto definitivo, que fue mecanografiado por Miroslav Petř́íček. El texto así conformado fue publicado por primera vez en 1983 en el cuarto volumen de la edición samizdat de las obras de Patočka, titulado El mundo natural y el movimiento de la existencia humana (Přirozený svět a pohyb lidské existence). En 1995 estas lecciones fueron editadas de nuevo en la editorial Oikoymenh, tras una nueva revisión de Jiř́ Polívka, Ivan Chvatík y Pavel Kouba. Ese texto de 1995 ha sido la referencia de nuestra traducción.

Estos detalles de la edición merecen un comentario adicional que se adelante a un posible reparo. En efecto, se trata de notas tomadas por varios alumnos. No

\footnotetext{
${ }^{6}$ Estas referencias sobre el texto han sido tomadas de los editores checos, cf. cf. Patočka (1995a), p. 203.
} 
es por tanto un texto escrito por el propio Patočka. No obstante, a mi juicio, hay razones suficientes para afirmar su plena fiabilidad. En primer lugar, los varios autores encargados de tomar notas aseguran el cotejo de sus versiones. Asimismo, se trata de personas que conocían bien al filósofo checo y su pensamiento. Por otro lado, el texto resulta consistente con el resto de su obra, especialmente con su pensamiento fenomenológico. Por lo demás, también contamos con las notas del propio autor para el curso, cuyo contenido a mi entender es coherente con el de estas notas. Están comprensiblemente en un estado más fragmentario, dado que eran para su uso personal, pero constituyen un excelente acompañamiento a este texto. ${ }^{7}$

En cuanto a la traducción, el responsable de la misma ha tenido que tomar algunas decisiones acerca de términos que espera estén suficientemente fundamentadas. En el caso de Patočka se presenta el problema de que sus explicaciones en checo incluyen traducciones propias de términos técnicos que con frecuencia llevan la marca de una interpretación personal. En algunos casos se incluyen explicaciones en notas al pie. De un modo general, me ha servido de apoyo la traducción al inglés de Erazim Kohák, quien ya en 1989 presentó una selección de este curso. ${ }^{8}$ Por último, es de justicia concluir con un agradecimiento explícito a los Archivos Jan Patočka de Praga por autorizar la traducción de estas lecciones. Esta expresión de gratitud se hace en especial a Ivan Chvatík, su director, quien lleva años promoviendo el conocimiento e investigación del gran filósofo checo.

${ }^{7}$ El lector interesado cuenta con una traducción al francés: Patočka, J. (1995b), pp. 53-116.

${ }^{8}$ Cf. Kohák (1989), pp. 274-284. Posteriormente se tradujo la totalidad de las lecciones: Patočka (1998). 


\section{BIBLIOGRAFÍA}

Barbaras, Renaud (2014). Introducción a una fenomenología de la vida. Madrid: Encuentro, pp.138-193.

Heitz, Michael y Nessler, Bernhard (eds.) (1999). Eugen Fink und Jan Patocka. Briefe und Dokumente. Múnich-Praga: Orbis Phaenomenologicus.

Kohák, Erazim (1989). "The movement of Human Existence. A Selection of Body, Community, Language, World". En ídem, Jan Patočka. Philosophy and Selected Writings, pp. 274-284. Chicago: University of Chicago Press.

Patočka, Jan (1995a). Tělo, společenství, jazyk, svět (cours de l'année universitaire 19681969), Praha: Oikoymenh.

Patočka,Jan(1995b). “Leçons sur la corporéité”.EnPatočka,Jan, Papiersphénoménologiques, pp. 53-116. Abrams, Erika (ed. y trad.). Grenoble: Millon.

Patočka, Jan (1998). Body, Community, Language, World. Kohák, Erazim (trad.). Chicago (II): Open Court.

Patočka, Jan (2004). "Universo y mundo del hombre. Observaciones a un planteamiento cosmológico contemporáneo". En El movimiento de la existencia humana. Padilla, Teresa, Ayuso, Jesús María, Serrano de Haro, Agustín (trads.). Madrid: Encuentro, 85-92. 